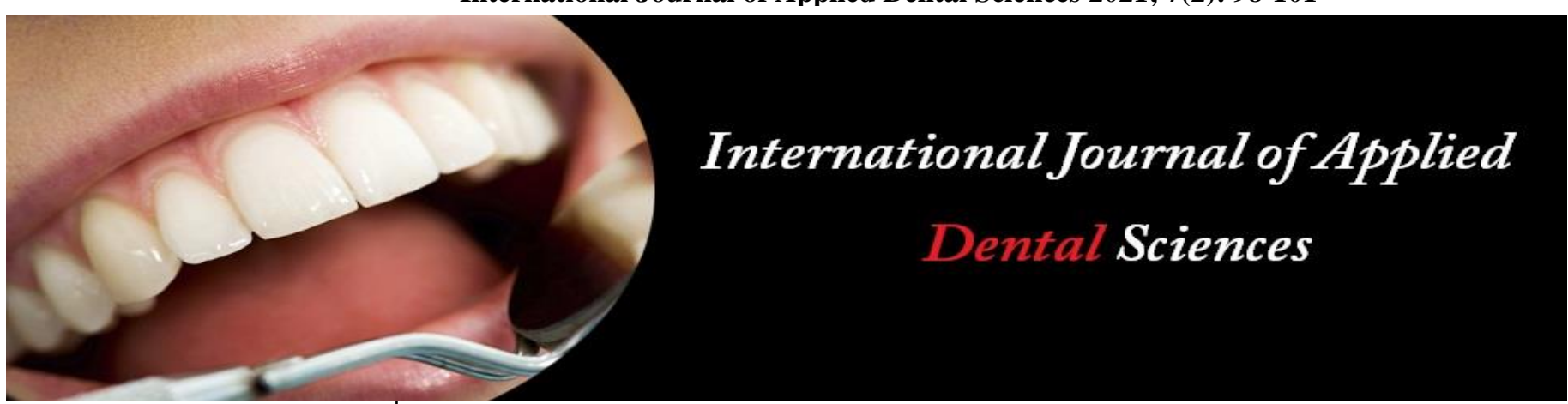

ISSN Print: 2394-7489

ISSN Online: 2394-7497

IJADS 2021; 7(2): 98-101

(C) 2021 IJADS

www.oraljournal.com

Received: 16-02-2021

Accepted: 18-03-2021

\section{Mehmet Eskibağlar}

Department of Endodontics,

Faculty of Dentistry, Dicle

University, Diyarbakir, Turkey

\section{Nezif Çelik}

Department of Endodontics,

Faculty of Dentistry, Harran

University, Sanliurfa, Turkey

Büşra Karaağaç Eskibağlar Department of Pediatric

Dentistry, Faculty of Dentistry,

Dicle University, Diyarbakir,

Turkey
Corresponding Author:

Mehmet Eskibağlar

Department of Endodontics,

Faculty of Dentistry, Dicle

University, Diyarbakir, Turkey

\section{Evaluating the frequency of patients' application to dentistry departments during the COVID-19 pandemic period and examining the reasons for application to the department of endodontics}

\author{
Mehmet Eskibağlar, Nezif Çelik and Büşra Karaağaç Eskibağlar
}

DOI: https://doi.org/10.22271/oral.2021.v7.i2b.1195

\section{Abstract}

Objective: The aim of the study is to assess the number of patients in terms of departments of dentistry, who applied to Dicle University Faculty of Dentistry during the period of COVID-19 pandemic, and to examine their causes of application to the endodontics clinic.

Material and Methods: Between the dates of 11 March 2020, the day COVID-19 was identified for the first time in Turkey, and 31 July 2020, the first clinic that the patients applied following the Department of oral diagnosis and radiology was taken as a basis. Additionally, patients applying to the department of endodontics were assessed clinically and radiologically, and their causes of visit were examined.

Result: Applied departments are determined respectively as follows: endodontics $(37,62 \%)$, oral and maxillofacial surgery $(25,32 \%)$, pediatric dentistry $(12,52 \%)$, periodontology $(8,11 \%)$, orthodontics $(7,02 \%)$, prosthodontics $(5,3 \%)$, and restorative dentistry $(4,04 \%)$. The reasons for applying to Endodontics are found respectively as follows: irreversible pulpitis $(44,02 \%)$, pulpal necrosis with symptomatic apical periodontitis $(22,33 \%)$, acute apical abscess $(18,01 \%)$, symptomatic apical periodontitis or acute apical abscess in endodontically treated teeth $(7,83 \%)$, chronic apical periodontitis $(4,12 \%)$, chronic apical abscess $(2,92 \%)$, and traumatic dental injures $(0,72 \%)$

Conclusion: Most of the patients, who applied to Faculty of Dentistry at Dicle University, were directed to department of endodontics. The cause of application to endodontics is identified mainly as irreversible pulpitis.

Keywords: COVID-19; dentistry; epidemiologic study

\section{Introduction}

Coronavirus emerged in the city of Wuhan in China's Hubei province in 2019 as an atypic and fast spreading pneumonia with an unknown etiology. It was announced by the Chinese Center for Disease Control and Prevention on 08 January 2020 that the pathogen causing this pneumonia was a novel Coronavirus $(\mathrm{CoV})^{[1]}$. The outbreak first spread to the other provinces in China, and then to the other countries. As of today, it has infected more than 15 million people, and has become a viral pandemic killing more than 632 thousand people. In Turkey, the first Coronavirus case was detected on 11 March 2020. By 31 July 2020, the virus infected over 227 thousand people, and killed more than 5 thousand.

The novel Coronavirus, also known as Coronaviridae, is an enveloped and single-stranded RNA virus. This virus family is known to be zoonotic and transmitted from animals to humans. This Coronavirus family initially caused Severe Acute Respiratory Syndrome (SARS$\mathrm{CoV}$ ) in 2002. Additionally, it was the factor for the Middle East Respiratory Syndrome (MERS-CoV) emerged in 2012. Since this novel Coronavirus shows genetical similarities with SARS-CoV and MERS-CoV, it was named 'the novel Coronavirus' (SARS-CoV-2) by the International Committee for Virus Taxonomy ${ }^{[2,3]}$. Moreover, the World Health Organization (WHO) named this infection COVID-19, caused by SARS-CoV-2 defined in $2019^{[4]}$. While it is known that the incubation period of this virus is 5-6 days, it can extend up to 14 days ${ }^{[5]}$.

The main modes of transmission for COVID-19 are respiratory droplets and contact of infected hands to face ${ }^{[6]}$. The droplets caused by the sneezes and coughs of infected patients might be inhaled by healthy individuals. 
Moreover, Coronavirus can stay on objects in the form of droplets and contamination. Afterwards, transmission might occur with the contact of healthy people to these objects.

Patients infected with COVID-19 show some symptoms. While many patients prove recovery with mild clinic symptoms similar to seasonal flu, some might show high fever, coughing, difficulty in breathing, abnormal findings in CT lung screening, muscle pain, nausea, vomiting, asthenia, and loss of taste. ${ }^{7}$ This highly infectious disease might also cause severe acute respiratory diseases ${ }^{[7,8]}$.

The purpose of this study is evaluating the frequency of patients' application to Dentistry Departments of Dicle University and examining the reasons for application to the Department of Endodontics during the COVID-19 pandemic period.

\section{Material and Method}

This study is based on the initial examination records of patients applied to Dicle University Department of Dentistry. The ethical protocol was conducted in accordance with the related directives of the Declaration of Helsinki, and ethical approval was obtained from the Ethical Committee of Dicle University Faculty of Dentistry (Document Number: 2020/33). The research consists of five different time periods starting from 11 March 2020, the date of the first case, and applications to seven different Departments of Dentistry.
These time periods were defined based on the dates of 11-31 March 2020, 1-30 April 2020, 1-31 May 2020, 1-31 June 2020 and 1-31 July 2020. The Departments of Dentistry are oral and maxillofacial surgery, endodontics, pediatric dentistry, periodontology, orthodontics, prosthodontics, and restorative dentistry. The first department applied after the department of oral diagnosis and radiology was evaluated, and only one application from each patient was accepted. The patients in the department of endodontics were evaluated as intraoral and extraoral, and their reasons for application were recorded. The data was examined through descriptive statistics. The statistical analysis of the data was conducted with SPSS Statistics V21.0 (IBM, Armonk, New York).

\section{Result}

Out of 7.013 patients included in the research, 3.811 are male, and 3.202 are female. The age range of the patients is 4-63, and the mean age is $34,23 \pm 1,78$. The average body temperature is $36.9^{\circ} \mathrm{C}$.

Following the department of oral diagnosis and radiology, the most applied department for all time periods was determined as endodontics $(37,62 \%)$. Endodontics was followed by oral and maxillofacial surgery $(25,32 \%)$, pediatric dentistry $(12,52 \%)$, periodontology $(8,11 \%)$, orthodontics $(7,02 \%)$, prosthodontics $(5,37 \%)$, and restorative dentistry $(4,04 \%)$ (Fig $1)$.

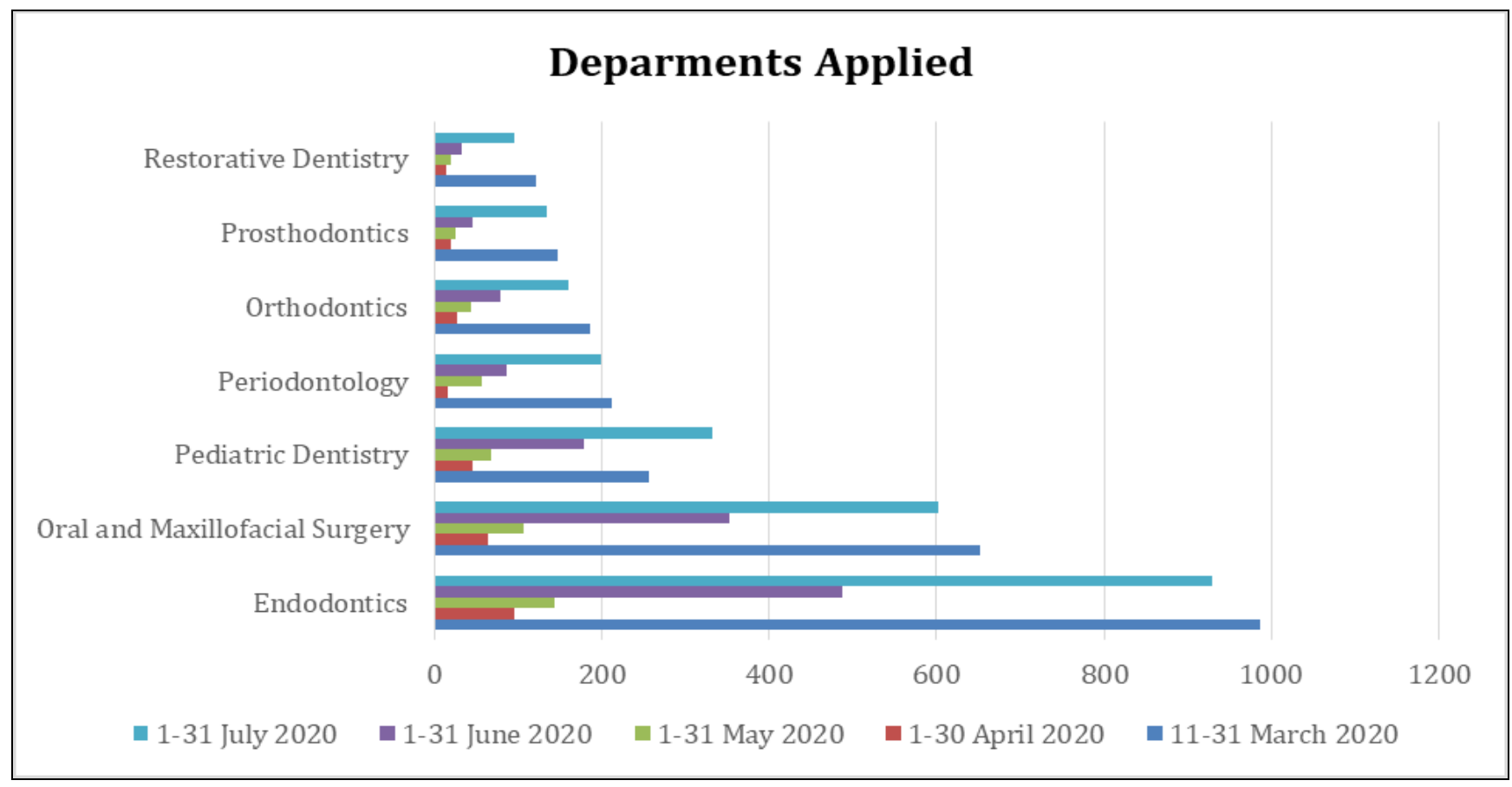

Fig 1: Departments applied based on date.

After the clinic and radiologic evaluation, the most prevalent diagnosis for patients applied to Endodontics was found to be irreversible pulpitis $(44,02 \%)$ for all time periods. This finding was followed by pulpal necrosis with symptomatic apical periodontitis $(22,33 \%)$, acute apical abscess $(18,01 \%)$, symptomatic apical periodontitis or acute apical abscess in endodontically treated teeth $(7,83 \%)$, chronic apical periodontitis $(4,12 \%)$, chronic apical abscess $(2,92 \%)$, and traumatic dental injures $(0,72 \%)$ (Fig 2). 


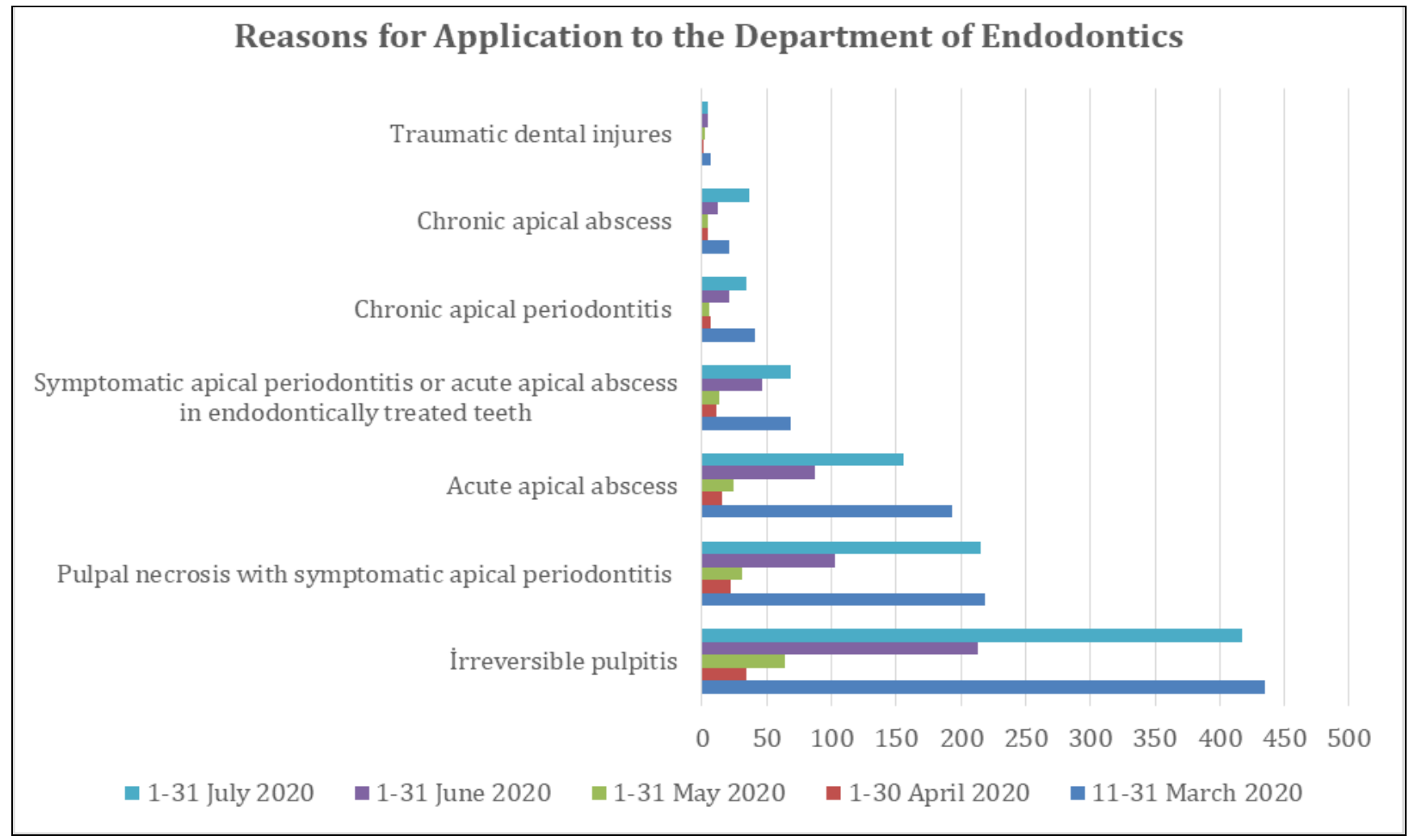

Fig 2: Diagnosis for the patients applied to the Department of Endodontics

\section{Discussion}

This study examines the patients who applied to the Faculty of Dentistry of Dicle University since 11 March 2020, when the first Coronavirus case was detected in Turkey. The decline in the number of applications could be explained with the postponement of nonemergent dental needs, the risk of Coronavirus infection, declaration of lockdowns etc.

Most of the patients whose applications are evaluated in the study are male. This is thought to be caused by that males conduct less oral hygiene practices than females, and that they have a higher level of dental anxiety ${ }^{[9,10]}$ Moreover, males' applying to dental emergency more frequently than females provide a correlation with the studies conducted in other countries in the world ${ }^{[11-15]}$.

Department of Endodontics is the most frequently applied department among all because most of the dental emergencies are included within endodontics. In our study, the primary reason for applying to Endodontics is found to be irreversible pulpitis, and then respectively pulpal necrosis with symptomatic apical periodontitis, acute apical abscess, symptomatic apical periodontitis or acute apical abscess in endodontically treated teeth, chronic apical periodontitis, chronic apical abscess, and traumatic dental injures. These findings are similar to those of other studies ${ }^{[13]}$.

\section{Conclusion}

Most of the patients applied to the Faculty of Dentistry of Dicle University during the pandemic due to toothache. As a result of the clinic and radiologic evaluation, the reason for the application of these patients, who were mainly directed to the department of endodontics, was found to be irreversible pulpitis.

\section{Reference}

1. Lu R, Zhao X, Li J, Niu P, Yang B, Wu H et al. Genomic characterisation and epidemiology of 2019 novel coronavirus: implications for virus origins and receptor binding. Lancet Glob Health 2020;395(10224):565-74.

2. Gorbalenya AE, Baker SC, Baric R, Groot RJd, Drosten C, Gulyaeva AA et al. Severe acute respiratory syndrome-related coronavirus: The species and its viruses-a statement of the Coronavirus Study Group 2020.

3. Zhu N, Zhang D, Wang W, Li X, Yang B, Song J et al. A novel coronavirus from patients with pneumonia in China, 2019. N Engl J Med 2020.

4. Singhal T. A review of coronavirus disease-2019 (COVID-19). Indian J. Pediatr. 2020, 1-6.

5. Backer JA, Klinkenberg D, Wallinga J. Incubation period of 2019 novel coronavirus (2019-nCoV) infections among travellers from Wuhan, China, 20-28 January 2020. Eurosurveillance 2020;25(5):2000062.

6. Dong E, Du H, Gardner L. An interactive web-based dashboard to track COVID-19 in real time. Lancet Infect Dis 2020;20(5):533-4.

7. Guan WJ, Ni ZY, Hu Y, Liang WH, Ou CQ, He JX et al. Clinical characteristics of 2019 novel coronavirus infection in China. MedRxiv 2020.

8. Chen N, Zhou M, Dong X, Qu J, Gong F, Han Y et al. Epidemiological and clinical characteristics of 99 cases of 2019 novel coronavirus pneumonia in Wuhan, China: a descriptive study. The Lancet 2020;395(10223):507-13.

9. Heft MW, Meng X, Bradley MM, Lang PJ. Gender differences in reported dental fear and fear of dental pain. Community Dent Oral Epidemiol 2007;35(6):421-8.

10. Vural UK, Öz FD, Dyrmıshı A, Gökalp S. Diş Hekimine Başvuran Hastaların Ağız-Diş Sağlığı Uygulamaları ile İlgili Bildirimleri. Turkiye Klinikleri J Dental Sci. 2013;19(3).

11. Sun BC, Chi DL, Schwarz E, Milgrom P, Yagapen A, Malveau $\mathrm{S}$ et al. Emergency department visits for nontraumatic dental problems: a mixed-methods study. Am J Public Health. 2015;105(5):947-55.

12. Lewis C, Lynch H, Johnston B. Dental complaints in 
emergency departments: a national perspective. Ann Emerg Med 2003;42(1):93-9.

13. Yu J, Zhang T, Zhao D, Haapasalo M, Shen Y. Characteristics of endodontic emergencies during COVID-19 outbreak in Wuhan. J Endod 2020.

14. Walker A, Probst JC, Martin AB, Bellinger JD, Merchant A. Analysis of hospital-based emergency department visits for dental caries in the United States in 2008. J Public Health Dent 2014;74(3):188-94.

15. Currie C, Stone S, Connolly J, Durham J. Dental pain in the medical emergency department: a cross-sectional study. J Oral Rehabil 2017;44(2):105-11. 